\title{
POLÍTICAS PÚBLICAS DE AGRICULTURA FAMILIAR PARA FOMENTAR A ECONOMIA DO MUNICÍPIO DE PRESIDENTE KENNEDY, ESPIRITO SANTO
}

\section{ARTIGO ORIGINAL}

MARROQUIM, Aline Rocha de Araújo ${ }^{1}$

ROZA, Flávia Soares ${ }^{2}$

FERREIRA, Geverson Batista ${ }^{3}$

SILVA, Joccitiel Dias da ${ }^{4}$

CARVALHO, Milene Rodrigues ${ }^{5}$

NASCIMENTO, Sheila Chaves Batista do ${ }^{6}$

SANT'ANNA, Tatiane Keila de Moura ${ }^{7}$

MARROQUIM, Aline Rocha de Araújo. Et al. Políticas Públicas de agricultura familiar para fomentar a economia do Município de Presidente Kennedy, Espirito Santo. Revista Científica Multidisciplinar Núcleo do Conhecimento. Ano 05, Ed. 05, Vol. 06, pp. 05-21. Maio de 2020. ISSN: 2448-0959, Link de acesso: https://www.nucleodoconhecimento.com.br/educacao/fomentar-a-economia

\footnotetext{
${ }^{1}$ Mestre em Ciência, Tecnologia e Educação pela Faculdade Vale do Cricaré.

${ }^{2}$ Mestre em Ciência, Tecnologia e Educação pela Faculdade Vale do Cricaré.

${ }^{3}$ Mestre em Ciência, Tecnologia e Educação pela Faculdade Vale do Cricaré.

${ }^{4}$ Doutor em Matemática pela UFRJ.

${ }^{5}$ Mestre em Ciência, Tecnologia e Educação pela Faculdade Vale do Cricaré.

${ }^{6}$ Mestre em Ciência, Tecnologia e Educação pela Faculdade Vale do Cricaré.

${ }^{7}$ Mestre em Ciência, Tecnologia e Educação pela Faculdade Vale do Cricaré.
} 


\section{RESUMO}

Este artigo teve como objetivo mostrar a importância do projeto da "Feira Livre Municipal". Pretende-se, com esta proposta, demonstrar como projeto ajuda na melhora da qualidade de vida na zona rural e como proporciona sustentabilidade no campo. Foi efetuada uma pesquisa exploratória por meio do método quantitativo. Destacou-se a importância da feira que se tornou uma referência de produtos orgânicos frescos e de qualidade, transformando, com isso, a vida de quem vende e de quem consome. Observou-se que há ainda muitas tarefas a serem cumpridas para que a Feira ganhe maior visibilidade e conquiste mais o mercado consumidor. $\mathrm{O}$ espaço físico precisa ser ampliado e ter um local mais apropriado para que possa acolher mais feirantes interessados no projeto, diversificando ainda mais os produtos oferecidos e dando mais conforto e comodidade ao consumidor final. A feira livre municipal tem gerado mais renda e qualidade de vida para os kennedenses, com a participação de 50 feirantes e de, em média, 600 famílias que se encontram em uma situação de vulnerabilidade possuem um ticket-feira. A Feira é vantajosa, também, para o produtor, pois a sua renda é aumentada em até $30 \%$.

Palavras-chave: Políticas públicas, agricultura familiar, Feira Livre Municipal, subsídios municipais.

\section{INTRODUÇÃO}

O bem-estar social requer a elaboração de planos gestores que visem a atenuar conflitos e a obtenção de ganhos, o que resultará no alcance do interesse comum. Tendo em vista a necessidade de amenizar o impacto da ausência de renda do pequeno produtor do município de Presidente Kennedy - ES, assim como a falta de estímulo dos mesmos (pela inexistência de projetos de comercialização de seus produtos), e, ainda, buscar soluções para atender socialmente famílias em vulnerabilidade, viu-se como uma alternativa viável a criação de uma feira, doravante conhecida como Feira Livre Municipal. Como o município de nosso estudo possui vocação agrícola, a Feira é relevante. Segundo Elenaldo (2002), a esfera municipal, com base política eleitoral nas elites proprietárias, não assume os riscos de uma 
política tributária mais realista. A política econômica neoliberal dá ênfase aos impactos sobre o emprego, na renda e nas condições de vida nos municípios.

Assim, os municípios se veem pressionados a realizar programas de geração de renda e emprego. A economia do país é forte na agricultura e acompanhando esse crescimento o município kennedense também possui uma economia bastante diversificada nesse setor. A partir desse pensamento analisou-se, neste artigo, uma das políticas públicas adotadas pela Prefeitura Municipal de Presidente Kennedy. Trata-se da Feira com ênfase na agricultura familiar. É uma forma de se fortalecer o comércio local. Conforme descrevem Gonçalves e Souza (2005), é localizável, na Constituição Federal, o conceito de propriedade familiar. Tal definição é amparada pelo inciso II, que é contemplado no artigo 4ํㅜ do Estatuto da Terra, estabelecido pela Lei no 4.504 , de 30 de novembro de 1964, com a seguinte redação:

[...] propriedade familiar: o imóvel que, direta e pessoalmente explorado pelo agricultor e sua família, Ihes absorva toda a força de trabalho, garantindo-Ihes a subsistência e o progresso social e econômico, com área máxima fixada para cada região e tipo de exploração, e eventualmente trabalhado com a ajuda de terceiros.

E, além disso, os autores também mencionam a definição da área máxima, na Lei no 8629, de 25 de fevereiro de 1993, que estabelece como pequena a extensão dos imóveis rurais com até quatro módulos fiscais, e como média propriedade aquelas entre quatro e 15 módulos fiscais, como elucida Bergamim (2016) em seu estudo. Buainaim e Romeiro (2000) apud Bergamim (2016, p. 211): "afirmam que a agricultura familiar desenvolve, em geral, sistemas complexos de produção, combinando várias culturas, criações animais e transformações primárias, tanto para o consumo da família quanto para o mercado". De acordo com os dados disponíveis no portal da prefeitura, a Feira Livre da Agricultura Familiar de Presidente Kennedy foi criada com o intuito de:

[...] incentivar os produtores do município. O projeto, mantido pela prefeitura, por meio das Secretarias de Desenvolvimento Econômico, 
Desenvolvimento da Agricultura e Pesca e de Assistência Social, já beneficiou mais de 50 famílias, que têm como fonte de renda a venda dos produtos no local. Outras 600 famílias são beneficiárias do programa Ticket Feira, que oferece a famílias carentes mais de $R \$ 100$ por mês para compras na Feira Livre e gera mais qualidade de vida para os kennedenses. O projeto se consolidou ao longo dos anos e em 2018 completou quatro anos. Alguns produtores, segundo a prefeitura, chegam a receber cerca de $\mathrm{R} \$ 5$ mil por mês, apenas com vendas do ticket feira no valor de $R \$ 30,00$ que é dado, semanalmente (PREFEITURA MUNICIPAL DE PRESIDENTE KENNEDY, 2019).

E, de acordo com informações da Secretaria de Assistência Social, os produtores passam por cursos regulares oferecidos pela Secretaria do Desenvolvimento em parceria com o Serviço de Apoio às Micro e Pequenas Empresas (Sebrae) para que recebam orientações e aprendam a agregar valor aos produtos. Além de frutas, verduras e legumes, também podem ser encontrados na Feira produtos da agroindústria, artesanatos e barracas de gastronomia. O local se tornou ponto de encontro das famílias todas às quintas-feiras, quando o encontro semanal é encerrado com um show (PREFEITURA MUNICIPAL DE PRESIDENTE KENNEDY, 2019).

\section{POLÍTICAS PÚBLICAS E AGRICULTURA FAMILIAR}

Segundo Nemet (2018), as Políticas Públicas são definidas como um conjunto de decisões, planos, metas e ações governamentais com a intenção de resolver os problemas de interesses públicos que podem ser específicos, como melhores condições na saúde pública. Contudo, ao olhar para o Estado, percebe-se como ele age aos conclames da sociedade (NEMET, 2018). Bourdieu e Passeron (apud SAVIANI, 1999, p. 18) enfatizam, ainda, a ideia de que:

Todo poder de violência simbólica, isto é, todo poder que chega a impor significações e a impô-las como legítimas, dissimulando as relações de força que estão na base da força, isto é, propriamente simbólica, a essas relações de força. 
Deste modo, percebe-se que, segundo Silva Filho (2018), que as políticas públicas se interligam às demandas da própria população, mas não necessariamente irão ser contempladas nas decisões da gestão, embora seja recomendado. Com base em uma visão geral de como a política pública é vista, o autor frisa que deve haver um equilíbrio entre a receita e as despesas. Silva Filho (2018) destaca, ainda, que as políticas públicas desencadeiam agentes mais transformadores e participativos, capazes, portanto, de modificar a própria realidade. Pode-se citar como exemplo os pequenos produtores que são responsáveis por mais da metade dos alimentos que chegam às mesas das famílias, segundo informações do Pronaf.

Nesse sentido, a implementação de políticas para auxiliar esses produtores é essencial para o desenvolvimento do setor econômico de nosso país. Para Mendes (2017), a agricultura familiar é um conceito que possui divergências em razão das suas definições múltiplas advindas dos mais diversos autores da área. Carneiro (1999), por exemplo, entende que esse tipo de agricultura pode ser definido como uma unidade de produção. Para Mendes (2017), essa unidade dá vida a uma estreita relação entre o trabalho, a terra e a família. Martins (2001), afirma que se trata de uma instituição que reproduz a lógica familiar no contato com a terra e a produção. Abramovay (1997, p. 3), por conseguinte, frisa que:

[...] é aquela em que a gestão, a propriedade e a maior parte do trabalho, vêm de indivíduos que mantêm entre si laços de sangue ou de casamento. Que esta definição não seja unânime e muitas vezes tampouco operacional. É perfeitamente compreensível, já que os diferentes setores sociais e suas representações constroem categorias científicas que servirão a certas finalidades práticas: a definição de agricultura familiar, para fins de atribuição de crédito, pode não ser exatamente a mesma daquela estabelecida com finalidades de quantificação estatística num estudo acadêmico. $O$ importante é que estes três atributos básicos (gestão, propriedade e trabalho familiar) estão presentes em todas elas. 
Pode-se, então, inferir que a agricultura familiar, no contexto brasileiro, como frisam Mendes (2017) e Silva Filho (2018), tomou forma em razão de desencadeamentos das esferas política, econômica e social. Eles se manifestam desde o período da colonização do Brasil e se fazem presentes até os dias atuais. Possuem características que fazem com que a agricultura tome forma a partir de um método que se ampara em técnicas da monocultura, e, ainda, latifundiárias, como elucida Mattei (2001, p. 1).

Durante o processo de modernização da agricultura brasileira, as políticas públicas para a área rural, em especial a política agrícola, privilegiaram os setores mais capitalizados e a esfera produtiva das commodities voltadas ao mercado internacional, com o objetivo de fazer frente aos desequilíbrios da balança comercial do país. Para o setor da produção familiar, o resultado dessas políticas foi altamente negativo, uma vez que grande parte desse segmento ficou à margem dos benefícios oferecidos pela política agrícola, sobretudo, nos campos do crédito rural, dos preços mínimos e do seguro da produção.

Para Fernandes (2013), ao se discutir sobre as políticas públicas no âmbito da agricultura familiar é preciso recuperar o cenário histórico brasileiro. As mudanças mais expressivas tomaram forma a partir de 1995, com a criação do Programa Nacional de Fortalecimento da Agricultura Familiar (PRONAF). O PRONAF fomentou um avanço significativo nesse tipo de agricultura, pois ele impulsionou a expansão desse setor. De acordo com Flores (2002), ele foi criado pelo governo federal e visa a promoção da geração de renda, de modo sustentável, por parte dos pequenos produtores rurais. Os movimentos sociais foram cruciais para que esses produtores tenham melhores condições hoje.

Até a década de 1990 não existia nenhuma política pública direcionada à este grupo (pequenos produtores), ou seja, não se contemplava a agricultura familiar no cenário político. Foi em razão dessa carência, segundo Bianchini (2015) e Fernandes (2013), que o PRONAF foi criado. Ele visa atender, sobretudo, a necessidade de crédito para o desenvolvimento desse tipo de atividade. O Ministério do Desenvolvimento Agrário 
(MDA), por sua vez, reitera e firma algumas das condições e requisitos para que esse produtores possam vir a ter acesso aos benefícios do PRONAF:

I. Explorar a parcela de terra em condição de proprietário, posseiro, arrendatário, parceiro ou concessionário (assentado) do Programa Nacional de Reforma Agrária (PNRA);

II. Residir na propriedade rural ou em local próximo;

III. Dispor, a qualquer título, de área inferior a quatro módulos fiscais;

IV. No mínimo $50 \%$ da renda familiar ser originária da exploração agropecuária e não agropecuária do estabelecimento;

V. O trabalho familiar deve ser a base do estabelecimento. Porém, é possível a contratação de empregados permanentes desde que a quantidade seja inferior ao número de pessoas da família ocupadas com o empreendimento familiar;

VI. Renda bruta familiar anual de $\mathrm{R} \$ 360.000,00$, incluída a renda proveniente de atividades desenvolvidas dentro do estabelecimento $\mathrm{e}$ fora dele, por qualquer membro da família.

Conforme Sena et al (2011 apud MATTEI, 2006, p. 104): "o "primeiro programa inteiramente voltado para a agricultura familiar, o Pronaf apresenta-se como primeiro passo no sentido de transformar a lógica predominante para o crédito rural na agricultura brasileira". Evidencia-se, dessa forma, que o PRONAF atua como um dispositivo crucial para que haja o fortalecimento da cultura da agricultura familiar. Desde a sua criação tem passado por diversas modificações, o que, automaticamente, implica-se na transformação do contexto rural brasileiro. $O$ acesso ao crédito do PRONAF contribuiu de modo expressivo para com a geração e manutenção dos empregos no campo. Serve, também, como um fator inibidor do êxodo rural. Segundo Aquino e Schneider (2010, p. 12), 
O estudo da Fundação de Economia de Campinas (FECAMP, 2002), por sua vez, detectou que os produtores que tiveram acesso aos recursos da política de crédito do Pronaf, em 2001, elevaram substancialmente o seu nível tecnológico e a produtividade agrícola dos seus estabelecimentos. Ou seja, os recursos do programa vêm contribuindo para que os agricultores familiares adotem técnicas agrícolas modernas, substituindo o crédito rural tradicionalmente destinado a comprar insumos químicos e máquinas.

Conforme Mendes (2017) alude, existem diversos fatores que fazem com que haja ou não acesso às políticas públicas no contexto rural, como, por exemplo, a burocracia, os juros altos, a dificuldade para se poder pagar empréstimos, a documentação da terra, a falta de interesse, dentre outros. O autor aponta que há, ainda, a falta de informações devido à não divulgação de dados sobre o programa, o que impede que essas políticas possam ser efetivamente gozadas. Deve-se levar em consideração, também, que muitos agricultores familiares precisam participar ativamente nesse processo de elaboração de políticas para que as suas demandas sejam efetivamente atendidas (MATTEI, 2006). Para tanto, é preciso que haja uma constante manutenção e aperfeiçoamento do programa (FERNANDES, 2013).

Nesse contexto, compreendemos que a agricultura familiar é um campo bastante promissor para que haja o desenvolvimento e fortalecimento do comércio local, porém uma série de medidas são essenciais para que seja possível gerar renda e, consequentemente, oportunidades a esses agricultores. O poder público municipal entendeu que, diante da realidade do município e da dificuldade de desenvolvimento dos agricultores com recursos próprios, precisavam de um estímulo para o aumento e a geração de renda, tirando-os da situação de vulnerabilidade. Os incentivos advém da disponibilização de itens como: sementes, adubo, poço artesiano com instalação da bomba, sombrite, caixa d'água, ração, materiais para a comercialização dos produtos (sacola, boné, jaleco, camisas, barraca com bancada, tendas), caixa para transporte de hortifrutigranjeiro, mesas, caminhão refrigerado e acompanhamento 
sistemático de equipe multidisciplinar, o que proporcionou maior credibilidade ao projeto.

\section{DO CAMPO PARA A MESA: A FEIRA LIVRE DE PRESIDENTE KENNEDY}

O site da prefeitura municipal de Presidente Kennedy disponibiliza alguns dados importantes para compreendermos a agricultura familiar do município. Ele se localiza no extremo sul do estado do Espírito Santo e possui uma latitude $21^{\circ} 05^{\prime} 56^{\prime \prime}$ sul e a uma longitude $41^{\circ} 02^{\prime} 48^{\prime \prime}$ oeste, estando a uma altitude de 55 metros (PREFEITURA MUNICIPAL DE PRESIDENTE KENNEDY, 2020). Estima-se que a população seja, de acordo com os dados do IBGE de 2014, de 11.221 habitantes. Possui uma área de $583,933 \mathrm{k}^{2}$. Os dados da prefeitura apontam que o município é um dos menos populosos de todos os estados do Espírito Santo, porém, por outro lado, possui o maior PIB per capita do país ( $\mathrm{R} \$ 815.093,79)$. Isso se dá em razão das explorações em alto mar da camada pré-sal no Oceano Atlântico pela Petrobras e outras empresas do ramo.

Ainda de acordo com informações do site, a economia de Presidente Kennedy é promovida a partir dos royalties do petróleo, o que melhora a economia do município em muitas áreas, inclusive a agricultura e a agricultura familiar. Buscando aumentar a renda das famílias camponesas, a prefeitura criou um programa de auxílio ao produtor rural e um local para venda dos seus produtos (PREFEITURA MUNICIPAL DE PRESIDENTE KENNEDY, 2020). A Feira Livre da Agricultura Familiar surgiu com a proposta de movimentar a economia local e incentivar os produtores do município.

As Secretarias de Desenvolvimento Econômico, Desenvolvimento da Agricultura e Pesca e de Assistência Social são as responsáveis por essa grande empreitada que tem dado certo desde a sua criação. Sobre os favorecidos, os órgãos apontam que o programa já contemplou mais de 50 famílias que possuem como fonte de renda a venda dos seus próprios produtos. Assim, ao todo 570 famílias são beneficiadas com o programa ticket feira, que oferece às famílias carentes o valor de 120,00 reais mensais a serem usados como crédito na Feira Livre, o que aumenta a qualidade de 
vida dessa população. Esse ticket é entregue semanalmente, no valor de 30,00 reais e não pode ser utilizado por terceiros, nem é acumulativo, o que faz com que toda semana haja fluxo de vendas.

A prefeitura relata ainda que esse projeto se concretizou ao longo dos anos e em 2018 completou 4 anos gerando renda regular a 50 agricultores familiares. Alguns produtores, segundo a prefeitura, chegam a receber cerca de $\mathrm{R} \$ 5$ mil por mês apenas com vendas do ticket feira, concedido a 600 famílias kennedense com comprovada vulnerabilidade socioeconômica. De acordo com informações da Secretaria de Assistência Social, os produtores passam por cursos regulares oferecidos pela Secretaria do Desenvolvimento em parceria com o Sebrae para que aprendam a agregar valor aos produtos.

Todos são qualificados para aprender o manejo das verduras, a produção, o tipo de solo propício para cada hortaliça, dentre outros. São oferecidos, também, cursos para melhor atenderem a população (PREFEITURA MUNICIPAL DE PRESIDENTE KENNEDY, 2020). Cabe, ainda, destacar que a feira é essencial para o desenvolvimento econômico da cidade, e, dessa forma, há a participação massiva da sociedade e do poder público nessa tarefa. Acredita-se que com o aumento populacional esperado para os próximos anos a Feira ganhe dimensões ainda maiores a ponto de ser conhecida em todo estado.

\section{INOVAÇÃO DE SUBSÍDIOS MUNICIPAIS NA AGRICULTURA} FAMILIAR

Dando origem a novos ciclos econômicos, o município vem inovando com a diversificação de produtos, aumento do consumo, do crédito e, certamente, visando o crescimento da economia. Estendendo esse conceito, o Instituto Inovação (2010) considera "que a inovação é a exploração com sucesso de novas ideias" e que esse sucesso implica em aumento de faturamento, margens de lucro. Começa, então, a ficar clara a diferenciação entre as possibilidades de inovar, com base em "inovações de produto ou de processo", e as possibilidades de inovar baseando-se no uso criativo 
de tecnologias existentes, mas aplicadas a novas situações de contorno, ou seja, de mercado.

Nesse contexto, percebe-se então que a agricultura somada à inovação é um grande desafio, até porque a inovação em todos os setores já se configura como um desafio. Assim sendo, é comum que os governos, em seus três instâncias, acionem recursos públicos e privados para chegar até essa inovação que, a cada dia, é mais cobrada. Práticas inovadoras devem ser capazes de conceber e difundir processos, produtos e serviços de forma mais dinâmica e moderna. Como destacamos, é algo a ser incorporado por todos os setores. Para que se mantenha a característica familiar da agricultura e, ao mesmo tempo, faça-se uso da inovação, é preciso que pelo menos um membro da família continue a desenvolver as atividades. Abramovay (1997, p. 3) explica que:

A agricultura familiar é aquela em que a gestão, a propriedade e a maior parte do trabalho, vêm de indivíduos que mantêm entre si laços de sangue ou de casamento. Que esta definição não seja unânime e muitas vezes tampouco operacional. É perfeitamente compreensível, já que os diferentes setores sociais e suas representações constroem categorias científicas que servirão a certas finalidades práticas: a definição de agricultura familiar, para fins de atribuição de crédito, pode não ser exatamente a mesma daquela estabelecida com finalidades de quantificação estatística num estudo acadêmico. O importante é que estes três atributos básicos (gestão, propriedade e trabalho familiar) estão presentes em todas elas.

Sendo assim, a inovação também atingiu a agricultura familiar que deixou de ser vista como uma cultura de subsistência para ganhar o status de geração de emprego e renda para as famílias campestres. A situação não é diferente se tratando dos residentes em Presidente Kennedy, pois a economia do município é, majoritariamente, pecuária e contempla atividades como o cultivo da mandioca, maracujá, cana-deaçúcar, leite, mamão e há, também, a exploração do petróleo. A cidade é considerada, também, como a maior produtora de leite de todo o estado. Os dados da prefeitura 
municipal apontam que a produtividade do setor rural é, em média, de $80 \%$ em termos de arrecadação. Abriga 70\% da população kennedense.

Cerca de mais de duas mil famílias têm a renda oriunda das atividades que envolvem cultivo. A prefeitura destaca, ainda, que a Secretaria de Desenvolvimento da Agricultura e Pesca, como forma de incentivar e auxiliar a produção agrícola, oferece recursos para 1.600 produtores. Para isso é preciso que eles estejam cadastrados. Eles são divididos entre as atividades que envolvem a pecuária, a agricultura e a pesca. Entre os dados divulgados pelo portal consta a notícia de que no período de julho 2016 a maio 2017 foram mais de 250 produtores atendidos com caminhões da eletrificação rural. Além disso, houve a construção de mata-burros, a distribuição e a instalação de manilhas, máquinas e tratores agrícolas gratuitos para atender às necessidades solicitadas.

Aumentou-se, a produtividade e, dessa forma, contribuiu-se de maneira direta para a escoação da produção numa nova relação direta entre produtor e consumidor. Segundo informações obtidas da Secretaria Municipal de Agricultura (acesso em 10 dez. 2018), o total de arrecadação do município está no leite (70\% dos recursos). Os dados da prefeitura municipal enfatizam que o município possui a maior bacia leiteira de todo o estado, pois, hoje, há, aproximadamente, 375 produtores de leite, e, dessa forma, a atividade desencadeia cerca de 1000 empregos no contexto rural. Sobre o apoio a esses pecuaristas, cabe ressaltar que é contemplado desde o tanque comunitário até a distribuição de 9.650 sacos de ração farelada mensais.

Diante dessa realidade foi criada a Lei Municipal oํ 1.100, de 24 de setembro de 2013, que institui o Programa Especial de Atendimento ao Produtor Rural no município de Presidente Kennedy (ES) e dá outras providências, conforme descrito em seu Artigo 1ํ, em que fica instituído o "Programa Especial de Atendimento ao Produtor Rural", com finalidade de realizar os serviços que venham beneficiar o produtor rural e o escoamento dos produtos até a Feira Livre. Essas medidas são inovações que valorizam o homem do campo e contribuem para que o mesmo permaneça na zona rural colaborando para o não crescimento desordenado da área urbana. 
A partir da popularização das atividades rurais, houve o aumento da produção agrícola, além de maiores e melhores condições do escoamento da produção. Assim, a agroindústria ganhou forças no município. E, tendo esse novo olhar sobre a agricultura familiar, o poder público municipal criou a política pública da "Feira Livre da Agricultura Familiar" como estratégia para gerar emprego e renda e também fomentar a economia local. A repercussão que ocorreu na vida dos feirantes deu-se de diversas formas, dentre elas o aumento da renda, a independência financeira, maior possibilidade de aquisição de veículos e eletrodomésticos, melhorias em construções e propriedades (por exemplo, a maioria dos feirantes não possuía veículos, o que hoje já é uma realidade para grande parte deles).

Isso permitiu aos agricultores terem a opção, já que não dependem, necessariamente, do transporte público para se locomoverem até a feira. Conforme é noticiado e reforçado pelos veículos de comunicação da cidade e dos entornos, a "Feira Livre da Agricultura Familiar" também incentiva cerca de 50 produtores rurais do município a se tornarem empreendedores (transformando em fonte de renda os produtos colhidos na horta, nos pomares, nos sítios e nas pequenas propriedades locais) para comercializarem no centro urbano o que plantam. De acordo com a Secretaria da Agricultura (acesso em 10 dez. 2018), considerando apenas o valor ticket feira, há uma movimentação de, no mínimo, $\mathrm{R} \$ 1,2$ milhões ao ano pela feira.

Em contrapartida ao trabalho do pequeno produtor rural, o poder público municipal promove a comercialização dos produtos dos pequenos produtores rurais em um local apropriado com infraestrutura composta por tendas, iluminação, palco e cadeiras (para barracas de gastronomia). Percebe-se que além do caráter econômico/social a feira também apresenta o caráter cultural de evento, que se tornou ponto de encontro da sociedade local. Em um único espaço, a Praça Manoel Fricks Jordão, pode-se encontrar os mais diversos produtos oriundos da produção dos agricultores da cidade.

Todas as quintas-feiras, o kennedense tem um motivo a mais para sair de casa, já que a feira oferece desde legumes, frutas, hortaliças, gastronomia até música com cantores regionais para formar um ponto de encontro das pessoas do município. Diante disso, fica evidente como a inovação resgatou a cultura de produção familiar 
de hortifrutigranjeiros e mudou a história das comunidades rurais do município desenvolvendo a valorização do homem do campo e devolvendo a dignidade para a população, que até então tinha como fonte de renda programas sociais (ESPÍRITO SANTO, 2020).

\section{METODOLOGIA}

Este artigo tem como escopo discutir sobre a agricultura familiar no contexto município de Presidente Kennedy, utilizando como eixo a Lei no 1121/2014 de criação da Feira Livre Municipal, obtidos entre 2014, 2015 e 2016, mas também retoma alguns dados históricos pertinentes e recentes sobre a cidade em questão. A fim de discutir sobre a importância da Feira no contexto dos kennedense, o estudo visou elencar as políticas públicas do município oriundas das secretarias de Desenvolvimento Econômico, Desenvolvimento da Agricultura e Pesca e de Assistência Social. Esses órgãos possuem informações relevantes sobre o cadastro do produtor rural e sobre as famílias beneficiadas com o ticket feira. Teve-se como objetivo analisar a abrangência dos programas que fomentam as atividades da agricultura familiar e verificar as políticas vigentes.

Investigou-se, ainda, a partir de dados secundários fornecidos pelos portais públicos estadual e municipal, as políticas agrícolas de outras dimensões governamentais a fim de se reconhecer as políticas vigentes em uma escala mais ampla, atenuando-se as diferentes formas de gestão das mesmas. A partir da observação direta foi feita, ainda, uma entrevista que se caracterizou como semiestruturada, efetuada no local da Feira Livre da Agricultura Familiar, na praça no centro da cidade de Presidente Kennedy. Buscou-se, a partir das respostas fornecidas, compreender a logística de funcionamento, os beneficiários atendidos e a população de um modo geral. Essas medidas foram utilizadas integralmente para a realização de um mapeamento, e, a partir dele, avaliou-se as políticas municipais, sobretudo $p$ que tange a agricultura familiar.

Além disso, tornou-se necessário, ainda, a realização de um levantamento de caráter biográfico a fim de verificar na literatura como os autores, a partir dos seus conceitos, 
teorias e instrumentos, têm se debruçado no que tange à temática da agricultura familiar, para, a partir disso, elencar algumas ações que podem potencializar a concretização efetiva das políticas públicas voltadas à esse público alvo, considerando, sempre, aspectos locais e regionais. Para fins de análise foi utilizada a abordagem qualitativa, a qual propiciou uma relação mais próxima entre pesquisador e pesquisado, permitindo que o pesquisador participasse de perto da realidade investigada. Para Richardson (2011, p. 79), "a abordagem qualitativa de um problema, além de ser uma opção do investigador, justifica-se, sobretudo, por ser uma forma adequada para entender a natureza de um fenômeno social".

\section{RESULTADOS E DISCUSSÕES}

Esta seção apresenta o resultado das entrevistas realizadas na Feira de Agricultura Familiar em Presidente Kennedy com os contemplados pelo ticket feira, com os feirantes e com os demais participantes da feira. A ferramenta metodológica utilizada foi a realização de entrevistas semiestruturadas. O primeiro grupo que foi entrevistado foi formado por cerca de 90 beneficiários do programa de políticas públicas do ticket feira. No que diz respeito a ocupação até o horário do início da feira, foi observado que decorrente do fato de que o benefício é entregue na parte da manhã e a feira inicia-se no período da tarde (a partir das 15 horas) as pessoas aproveitam o tempo ocioso para resolver outros afazeres como, por exemplo, serviços em bancos, correios, consultas, lojas, dentre outros.

Durante a entrevista, informações importantes foram aparecendo de forma espontânea, tais como os relatos de que a logística é muito desgastante, pois as pessoas ficam sem comer e em pé na fila durante horas para receberem o ticket. $\mathrm{Na}$ opinião dos entrevistados, o benefício poderia ser entregue em outro local, que fosse fechado, para que os beneficiários não ficassem expostos como ficam na rua e que o mesmo poderia ser entregue mensalmente para amenizar os transtornos descritos. Para minimizar o tempo aguardado, sugere-se a ampliação dos horários do transporte público gratuito ou que a distribuição do ticket (que é feita pela Secretaria de Assistência Social) passe a ser realizada em horário mais próximo ao de abertura da 
feira para que, assim, não haja a necessidade dos beneficiados do ticket feira ficarem o dia inteiro fora das comunidades deles.

No que tange a qualidade dos produtos disponibilizados para aquisição, os entrevistados afirmaram que são de excelência. Este dado é bastante relevante, pois representa o sucesso do projeto em oferecer alimentos de qualidade para a população de baixa renda. Atualmente, a qualidade e a produtividade são preocupações em todo o mundo. Nas palavras de Barcellos (2008) isto se traduz no desempenho dos resultados, sendo que todos os esforços organizacionais estão voltados à aspectos tangentes ao desenvolvimento sustentável e à melhora da qualidade de vida. $\mathrm{O}$ segundo grupo entrevistado no dia da feira foi formado pelos produtores dos produtos disponibilizados na "Feira Livre Municipal". Foram cerca de 30 feirantes, os quais responderam as seis (06) perguntas direcionadas.

$\mathrm{Na}$ entrevista com esse grupo chegou-se à conclusão de que a grande maioria dos produtos comercializados na feira são produzidos por eles mesmos e que numa proporção menor os outros produtos que são vendidos no local se dão por meio de parcerias com outros produtores do próprio município ou de cidades vizinhas. Bezerra e Schlindwein (2017, p. 5) apontam que: "o desenvolvimento local é baseado nos agentes locais, sendo relacionado a iniciativas inovadoras da coletividade, encadeando as potencialidades locais nas condições dadas pelo contexto". Frisam, ainda, que para que o desenvolvimento de tais atividades dure por anos, deve-se elevar as oportunidades sociais e estimular a competitividade da economia local. Buarque (199) entende que esse fator aumenta a renda.

Quando foram indagados sobre o que a feira representa para eles a resposta foi diversa, dependendo da visão que o feirante tem sobre a feira. Um número elevado disse que a comercialização dos produtos na feira municipal representa melhoria nas vendas. Outros afirmaram que se trata de uma geração de renda, e ainda houve um grupo de menor proporção que relatou tratar-se de uma terapia. Bezerra e Schlindwein (2017, p. 9) frisam que: "terra é sinônimo de vida e trabalho e, sem dúvida, os agricultores familiares vêm trabalhando arduamente para conquistarem uma vida 
digna no meio rural". Assim, para os autores, buscar diferentes estratégias para diversificar a fonte de renda é essencial.

As respostas coletadas exemplificam que o objetivo do projeto da "Feira Livre Municipal" cumpre o principal objetivo a que se propôs, que é oportunizar ao pequeno produtor melhoria nas vendas dos produtos da agricultura familiar. Os entrevistados relataram melhoria nas vendas graças ao fato de terem um local apropriado, com um dia predeterminado e com um público-alvo definido. O terceiro e último grupo a participar da entrevista foi formado pelos consumidores em geral. Ao todo participaram da pesquisa 90 consumidores. Foi perguntado a respeito da opinião deles sobre a feira. Os entrevistados responderam que a população kennedense considera a feira uma ótima ideia tendo conquistado a população e sendo, portanto, importante para a vida das pessoas e para o desenvolvimento local.

Mascarenhas e Dolzani (2008, p. 75), em seu estudo, reiteram que a feira livre no Brasil "[...] constitui modalidade de mercado varejista ao ar livre, de periodicidade semanal, organizada como serviço de utilidade pública pela municipalidade e voltada para a distribuição local de gêneros alimentícios e produtos básicos". Os entrevistados relataram, também, que há diferença de preços entre a feira e os preços praticados no comércio local, sendo que na feira os produtos apresentam um valor maior. Constatou-se, por meio das respostas dadas pelos consumidores, que a qualidade dos produtos da feira é melhor do que a dos oferecidos nos supermercados.

Ficou evidente, desse modo, que há a necessidade de implementação de políticas públicas para que o produtor da agricultura familiar consiga oferecer produtos de qualidade com preços acessíveis e, com isso, consiga concorrer com o comércio tendo igualdade de condições. Tal atitude geraria ganhos para todos os envolvidos: produtores e consumidores. Conforme evidenciaram os dados levantados, com relação à parte cultural da Feira foi considerada positiva pela maioria. Para Anjos et al (2005), os aspectos econômicos somados aos sociais e simbólicos aparecem na expectativa dos consumidores da Feira. Dessa forma, as feiras livres não podem ser compreendidas, apenas, como um sistema de comercialização, devido ao apego emocional e simbólico dos frequentadores. 
Assim, essas feiras, como é o caso da de Presidente Kennedy, são defendidas como pertencentes e indispensáveis para a manutenção da tradição regional de um determinado município. Essas feiras carregam traços culturais marcantes da cidade que representam, e, dessa forma, exercem um papel se suma importância social e cultural na vida dos kennedenses. Foi relatado, durante a entrevista, que quando há shows a população fica mais tempo consumindo na feira e, consequentemente, há o aumento das vendas do dia. Além disso, também foi dito pelos entrevistados que a feira é utilizada para valorizar e promover os chamados "Artistas da Terra" divulgando a gastronomia e a cultura locais em um único espaço.

É uma forma, então, de se preservar a riqueza cultural do município. Já no que se refere à pergunta sobre as atrações musicais, a maioria dos entrevistados respondeu que deveriam ser feitos mais investimentos na estrutura da feira. Outros participantes sugeriram a ampliação dos horários do transporte municipal (Transkennedy) para que haja melhor aproveitamento das atrações musicais noturnas.

\section{CONSIDERAÇÕES FINAIS}

A partir da pesquisa observou-se que as políticas públicas do município de Presidente Kennedy causaram um impacto expressivo na vida dos residentes com a implementação da "Feira Livre". Ela valoriza a agricultura familiar e estimula a sua continuidade. A inovação vem refletindo na melhoria dos produtos levados para a feira, agregando, assim, valor aos mesmos e diferenciando-os na forma como os produtos são oferecidos ao mercado consumidor, possibilitando, também, o aumento do nível de emprego e renda da população kennedense. Considera-se que este projeto tem transformado a vida de produtores e das famílias envolvidas, não só no que diz respeito a fonte de renda, mas, também, a qualidade de vida.

O município vem mostrando, por meio de suas políticas públicas, que realmente possui uma gestão comprometida com o desenvolvimento local. A população tem abraçado o projeto comparecendo em massa, às quintas-feiras, no espaço. Acreditase que o projeto Feira Livre Municipal contribui, sobretudo, para valorizar o produtor da agricultura familiar, artesanal e o artista popular regional, o que traz benefícios para 
toda a sociedade. Percebe-se que sua consolidação proporciona uma nova visão sobre os produtos advindos da agricultura familiar e da atividade artesanal, considerando os aspectos sociais e de desenvolvimento sustentável. Tais fatores fazem da Feira indispensável para o município.

Recomenda-se, às secretarias envolvidas, a aquisição de estrutura física fixa, além da constante capacitação dos feirantes e das visitas técnicas a feiras de pequeno e grande porte, para que possam visualizar seus principais desafios e lidarem com outras realidades. Além disso, a ampliação dos horários do transporte público gratuito nos dias de feira para que realmente atenda às reais necessidades dos beneficiados e, assim, possam desfrutar plenamente, das atividades da feira municipal é essencial. Dado o exposto, conclui-se que a implementação de políticas públicas pode e deve ser uma solução, um caminho para o desenvolvimento local e, consequentemente, para que se possa viver de forma saudável e sustentável.

\section{REFERÊNCIAS}

ABRAMOVAY, R. Paradigmas do capitalismo agrário em questão. São Paulo: Anpocs, Unicamp, Hucitec, 1997.

ALMEIDA, R. A. de.; KUDLAVICZ, M. A potencialidade da pequena unidade de produção em Mato Grosso do Sul: os censos agropecuários 1995/96 e 2006 em debate. In: FAISTING, A. L.; FARIAS, M de F. L. de (Org.). Direitos humanos, diversidade e movimentos sociais: um diálogo necessário. Dourados, MS: Ed. UFGD, 2011. p. 45-66.

ANJOS, F. S. dos.; GODOY, W. I.; CALDAS, N. V. As feiras-livres de Pelotas sob o império da globalização: perspectivas e tendências. $1^{a}$ ed. Pelotas: Editora e Gráfica Universitária, 2005.

BARCELLOS, P. F. P. Agility and customer satisfaction: a strategic weapon for small and mid-sized business. In: 10th West Lake International Conference on Small and Medium Business, 2008. 
BERGAMIM, J. S. Impactos ambientais e agricultura familiar: como esta relação apresenta-se no espaço rural paranaense. Ciência e Natura, v. 38, n. 1, p. 206-214, 2016.

BEZERRA, G. J.; SCHLINDWEIN, M. M. Agricultura familiar como geração de renda e desenvolvimento local: uma análise para Dourados, MS, Brasil. Interações (Campo Grande), v. 18, n. 1, p. 3-15, 2017.

BIANCHINI, V. Vinte anos do Pronaf - 1995-2015: Avanços e desafios. Brasília: Ministério do Desenvolvimento Agrário (MDA), 2015.

BOURDIEU, P. O poder Simbólico. Rio de Janeiro: Difel, 1859.

BRASIL. Lei no 1100/2013. 24/09/2013. Institui o Programa Especial de Atendimento ao Produtor Rural no município de Presidente Kennedy (ES) e dá outras providências. Disponível em: legislacaocompilada.com.br/kennedy/Arquivo/Documents/.../html/L11002013.html. Acesso em: 09 dez. 2018.

BUAINAIM, A. M.; ROMEIRO, A. R. A agricultura familiar no Brasil: agricultura familiar e sistema de produção. Projeto: UTF/BRA/051/BRA. 2000. Disponível em: http://www.incra.gov.br/fao. Acesso em: 01 dez. 2018.

BUARQUE, S. J. C. Metodologia de planejamento do desenvolvimento local e municipal sustentável. Material para orientação técnica e treinamento de multiplicadores e técnicos em planejamento local e municipal. Brasília, DF: IICA, 1999.

CARNEIRO, M. J. T. Agricultores familiares e pluriatividades: tipologias e políticas. In: COSTA, L. F. C.; MOREIRA, R. J.; BRUNO, R. (Orgs.). Mundo rural e tempo presente. Rio de Janeiro: Mauad/Pronex, 1999.

CNBB. Igreja e Questão Agrária no Início do Século XXI. Brasília: Estudos CNB, 2010. 
ELENALDO, C. T. O papel das políticas públicas no desenvolvimento local e na transformação da realidade. Políticas públicas - O papel das políticas públicas. 2002 AATR-BA. Disponível em: http://www.dhnet.org.br/dados/cursos/aatr2/a_pdf/03_aatr_pp_papel.pdf. Acesso em: $01 \mathrm{dez} .2018$.

ESPÍRITO SANTO. Secretaria de Estado da Agricultura, Abastecimento, Aquicultura e Pesca (Seag). Governo e prefeitura investem na agricultura familiar de Presidente Kennedy. Texto atualizado em 07/03/2017. Disponível em: https://seag.es.gov.br/governo-e-prefeitura-investem-na-agricultura. Acesso em: 09 dez. 2018.

FERNANDES, A. M. S. O PRONAF na agricultura familiar: sua criação, distribuição e principais resultados. 2013. 57 f. Trabalho de Conclusão de Curso (Bacharel em Economia) - Universidade Federal do Rio Grande do Sul, Porto Alegre, 2013.

GONÇALVES, J. S.; SOUZA, S. A. M. Agricultura familiar: limites do conceito e evolução do crédito. Artigos: políticas públicas. Instituto de Economia Agrícola. Disponível em: http://www.iea.sp.gov.br/out/verTexto.php?codTexto=2521. Acesso em: 01 dez. 2018.

MASCARENHAS, G.; DOLZANI, M. C. da. Silva. Feira livre: territorialidade popular e cultura na metrópole contemporânea. Revista Eletrônica Ateliê Geográfico, v. 2, n. 4, p. 72-87, agosto. 2008.

MATTEI, L. Políticas públicas de fomento à produção familiar no Brasil: o caso recente do Pronaf. Florianópolis: UFSC, 2001. Disponível em: http://www.sober.org.br/palestra/5/421. Acesso em: 10 dez. 2018.

MATTEI, L. Pronaf 10 anos: mapa da produção acadêmica. Brasília: Ministério do Desenvolvimento Agrário (MDA) / NEAD (Estudos, n. 12), 2006.

MENDES, A. de. M. Acesso às Políticas Públicas no Meio Rural: Um Estudo a Partir dos Agricultores Familiares do Ramal do Brasileirinho, Manaus - AM. Revista 
Científica Multidisciplinar Núcleo do Conhecimento, Edição 9, Ano 02, v. 1, p. 529, dez. 2017.

NEMET, F. R. Políticas públicas e seus impactos na sociedade. 2018. Disponível em: http://folhacarapicuibana.com.br/2018/07/31/caminhos-para-refletir-sobrepoliticas-publicas-tomando-como-exemplo-o-municipio-de-carapicuiba-na-regiaometropolitana-de-sao-paulo-por-prof-a-fabiana-rodovalho-nemet/. Acesso em: 12 mai. 2020.

PREFEITURA MUNICIPAL DE PRESIDENTE KENNEDY. Feira Livre. Disponível em: https://www.presidentekennedy.es.gov.br/noticia/ler/2542/feira-livre-municipal. Acesso em: 10 dez. 2018.

SENA, J. O. et al. Recursos financeiros do Pronaf: um estudo do planejamento e controle realizados pelos agricultores familiares das associações comunitárias do Vale do Bananal. In: Encontro Nacional de Pós-Graduação em Administração, 2011.

SILVA FILHO, V. F. da. Políticas Públicas e seus Impactos na Sociedade. Revista Científica Multidisciplinar Núcleo do Conhecimento, Ano 03, Ed. 05, v. 2, p. 127138, mai. 2018.

WANDERLEY, M. de. N. B. Raízes Históricas do Campesinato Brasileiro. In: TEDESCO, João Carlos (org.). Agricultura Familiar Realidades e Perspectivas. $2^{\underline{a}}$ ed. Passo Fundo: EDIUPF, 1999.

Enviado: Fevereiro, 2020.

Aprovado: Maio, 2020. 